\title{
Harmonic enhancement in microgrid with applications on sensitive loads
}

\author{
Montaserbillah Hafez, Hussein El-Eissawi, Nabil Ayad \\ Egyptian Atomic Energy Authority, Nuclear Research Center, Cairo, Egypt
}

\begin{tabular}{l}
\hline \hline Article Info \\
\hline Article history: \\
Received Aug 9, 2018 \\
Revised Nov 2, 2018 \\
Accepted Nov 23, 2018 \\
\hline Keywords: \\
ETAP \\
Harmonic distortion \\
Microgrid \\
Passive filter \\
Power quality
\end{tabular}

\begin{abstract}
Power quality issues are an important and growing problem in microgrid. There are two reasons; the more active consumer is participating in the power sector, the use of renewable energy which having a great impact on voltage variation. This paper discusses power quality disturbance and especially harmonic distortion issues in microgrid, and suggests a solution to maintain the operation of the distribution system within power quality standard. To protect sensitive loads from harmonics produced by the grid and by renewable energy sources, passive harmonic filter has been proposed in this paper. The electrical system of a nuclear research reactor as sensitive loads is designed by using Electrical Transient Analyzer Program (ETAP) software. The results show these technical issues are presented with their influence on electrical voltage and harmonic specter.
\end{abstract}

Copyright $\odot 2019$ Institute of Advanced Engineering and Science. All rights reserved.

Corresponding Author:

Montaserbillah Hafez,

Egyptian Atomic Energy Authority,

Nuclear Research Center, Cairo, Egypt.

Email: eng.mon@ hotmail.com

\section{INTRODUCTION}

The modern microgrid has brought large challenges to controlling the power quality. Because of the demands for extremely efficient consumption, the diversity of loads, in addition to the use of renewable energy source (Photovoltaic (PV), biomass, wind, etc.) generation source, and grid connection technology through the power electronics borders [1], [2].

The Electrical Power Quality is the supply of reliable power to its customer at designed rating of voltage and frequency with ideal sinusoidal voltage and current waveform [3], it is affected due to various reasons in modern power electronic world because of the usage of power electronic semiconductor based devices and power quality disturbances [4], [5].The definition of Power quality according to the IEEE Standard "The concept of powering and grounding electronic equipment in a manner suitable to the operation of that equipment and compatible with the premise wiring system and other connected equipment" [6]. Power quality problem include phenomena such as voltage fluctuation, voltage unbalance, very short interruptions, voltage sag, and harmonics distortion [7], [8]. This paper deals with reduction of devastation effects caused by harmonics which is type of power quality problem.

Harmonic distortion causes some unexpected conditions on the electrical system. Harmonic distortion can decrease the accuracy of the electrical meter. Harmonic distortion may also cause excessive dissipation of electrical equipment so as to increase the cost of the bill [9], [10]. Furthermore, harmonic distortion causes electrical equipment not to work on the specified power quality standards causing a decrease in the lifetime of the electrical equipment [11], [12]. The harmonics generation from renewable energy source depends on the type of inverters will be divergent. In Photovoltaic depends on the type of control strategy and the size of PV systems and also on the grid voltage harmonics [13]. In wind energy, the converter is used to convert variable voltage from the induction generator to DC voltage, just like that producing DC power. The DC voltage is converted to AC voltage that is suitable for electrical operations in 
the grid. However, the use of converters injects a high intensity of current harmonic low frequency content into the power system [2].

Employing active and passive filters can improve the power factor and minimize harmonic currents. Active filters are highly flexible, but they increase system complexity and costs [14]. Passive filters are simpler and more economic, offering both the power-factor correction and high current-filtering capacity [15]. They also reduce harmonic voltages in installations where the supply voltage is disturbed [16]. Various methods have been proposed for designing the passive filters [17]-[20]. The goal is to minimize the harmonic impedance at specific frequencies and to maximize the fundamental frequency impedance of the filter for minimizing losses. However, re-calculations are required for each load change [16].

In this research, the nuclear research reactor is the case study to reduce the harmonic distortion. The authors design of single-tuned passive filter for suppressing the harmonic currents. Two types of harmonics produced by the grid and by renewable energy sources are modeled using ETAP. The limitation of harmonics pollution present at the point of common coupling (PCC) had been control by IEEE Std. 519 to improve the power quality, which widely accepted in nuclear research reactor.

\section{PASSIVE HARMONICS FILTERS}

For mitigating the harmonic distortion passive filtering is the simplest conventional solution [21]. Passive elements like resistance, inductance and capacitance are used by the passive filters to control the harmonics. Common types of passive filters and their configurations are depicted in Figure 1.

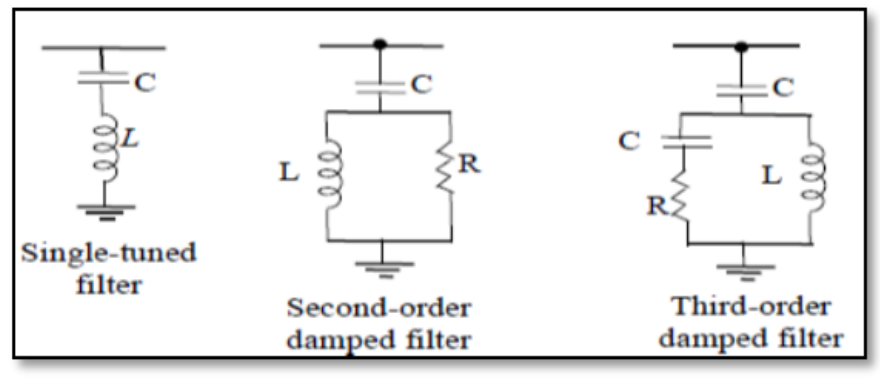

Figure 1. Passive power filters

The shunt connection of passive filters with the power system provides least impedance path to the harmonic current at tuning frequency. As compared to the shunt filter series filter is designed to carry full load current therefore they need over current protection devices. Whereas shunt passive filter carries a fraction of series filter current. The series filter is relatively more expensive hence shunt passive filter is commonly used as harmonic filter. Furthermore it also provides reactive power at system operating frequency.

The most use of passive filter is a Single Tuned Filter (STF). The most commonly used passive filter is the single-tuned filter. This filter is simple and least expensive as compared with other means for mitigating the harmonic problems [22], [23]. The LC STF (Single Series Filter) is most common and inexpensive type of passive filter. This filter is connected in shunt with the main distribution system and is tuned to present low impedance to a particular harmonic frequency. Therefore; harmonic currents are diverted from the least impedance path through the filter. For designing the single tuned filter it is essential to select the appropriate capacitor value that enables good power factor at system frequency. Placing these filters in close proximity to the disturbing devices is a more expensive solution, but it is a solution that provides reduced losses in the power network [24], [25].

\section{ETAP SIMULATION AND MITIGATION OF HARMONICS}

\subsection{Brief introduction of ETAP software}

ETAP is a comprehensive analysis tool for power system design and testing developed by OTI company. ETAP is enterprise software with fully graphical interface. It can switch multiple functional interfaces in the same program and the operation is very convenient. The ETAP harmonic analysis module can simulate various power components and devices accurately. The module has two analysis methods: harmonic wave power flow and harmonic frequency scan. In order to explore the harmonic distortion and 
diffusion characteristics in the nuclear research reactor, this paper conducts the analysis and calculation using the harmonic analysis tool in ETAP. This tool, which complies with IEEE 519 standards, embedded the power flow algorithm of Newton- Raphson and Gauss-Seidel and can customize the harmonic source model, is able to evaluate the distortion rate and system resonance quickly.

\subsection{ETAP simulation of electrical system for nuclear research reactor}

In this paper, the microgrid of nuclear research reactor is simulation by ETAP 12.6. A feeder with short-circuit power Ssc=65 MVAsc connected to the $11 \mathrm{kV}$ bus, bus 2 (PCC) connected to the $11 \mathrm{kV}$ bus via $500 \mathrm{kVA}(11 / 0.4 \mathrm{kV})$ transformer. There are four lumped loads (two static loads and the other two are motor loads), $100 \mathrm{KVA}$ each. In addition, the Renewable energy source contains photovoltaic panels (150 KVA) and wind turbines (400 KVA) are connected to bus 3. Lumped load 5 is an external load. The circuit diagram is shown in Figure 2, and the relevant element parameters are shown in the diagram. There are two study cases of source of harmonic and effected on PCC.

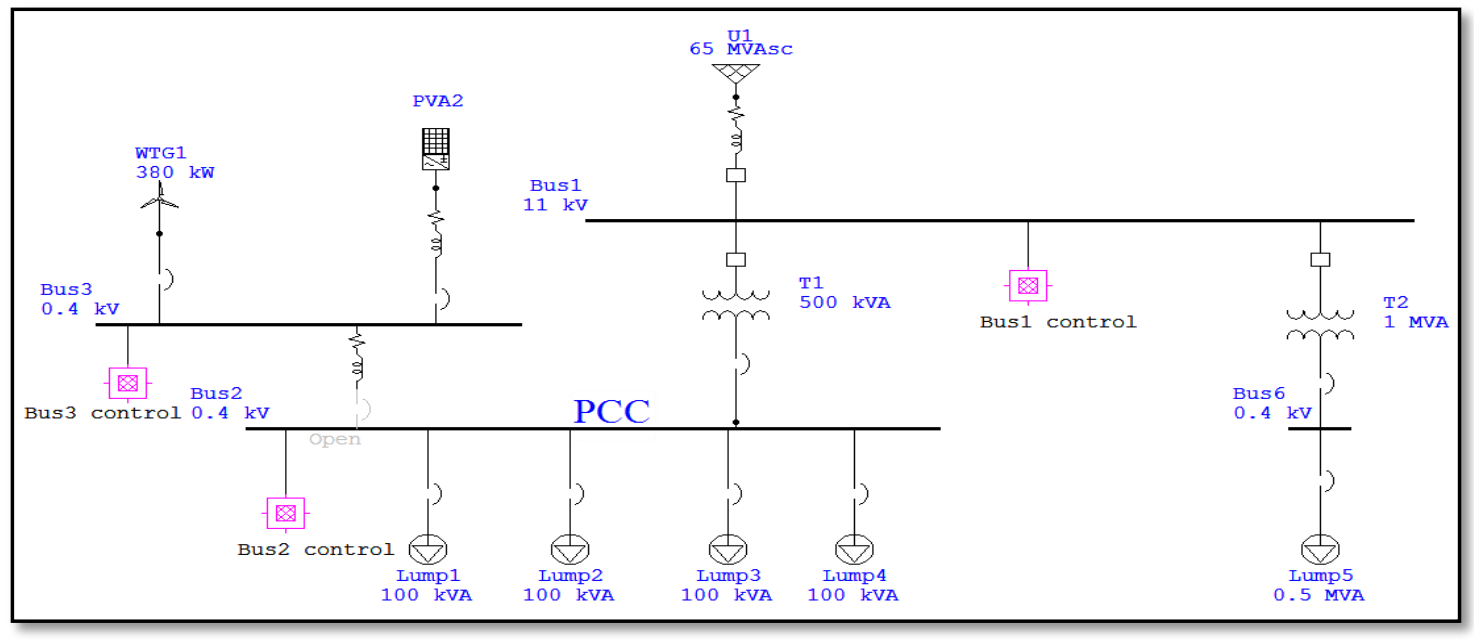

Figure 2. Circuit model in ETAP 12.6

Case 1: Harmonic from Grid:

The source of harmonic is the grid and effect on the PCC, bus 3 is disconnected. First step in this study was to assess the harmonic distortion of the PCC without any technical solution addition, for distortion mitigation. After performing the harmonic power flow simulation is shown in Figure 3, the results of THD values of the buses. IEEE 519 standard of limits of harmonic voltage are shown in Table 1.

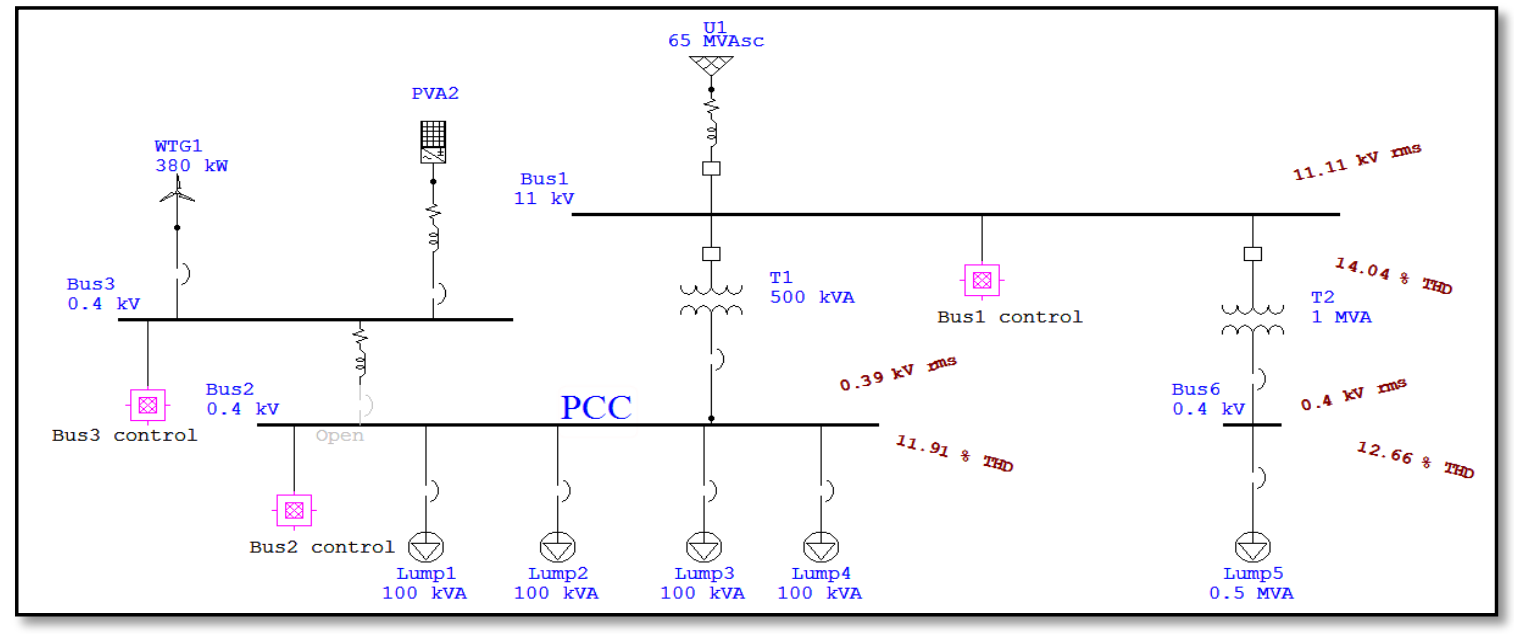

Figure 3. Harmonic flow simulations without filters 
Table 1. Voltage Distortion Limits

\begin{tabular}{ccc}
\hline Bus voltage $\mathrm{V}$ & Individual harmonic & Total harmonic distortion THD \\
at PCC & $(\%)$ & $(\%)$ \\
\hline$V \leq 1.0 \mathrm{kV}$ & 5.0 & 8.0 \\
$1 \mathrm{kV}<V \leq 69 \mathrm{kV}$ & 3.0 & 5.0 \\
$6 \mathrm{kV}<V \leq 161 \mathrm{kV}$ & 1.5 & 2.5 \\
$161 \mathrm{kV}<V$ & 1.0 & 1.5 \\
\hline
\end{tabular}

It can be seen that there are a serious harmonic pollution in bus 2 (PCC) complies with IEEE 519 standards. Figure 4 represents the value of harmonic spectrum for the voltage of the PCC.

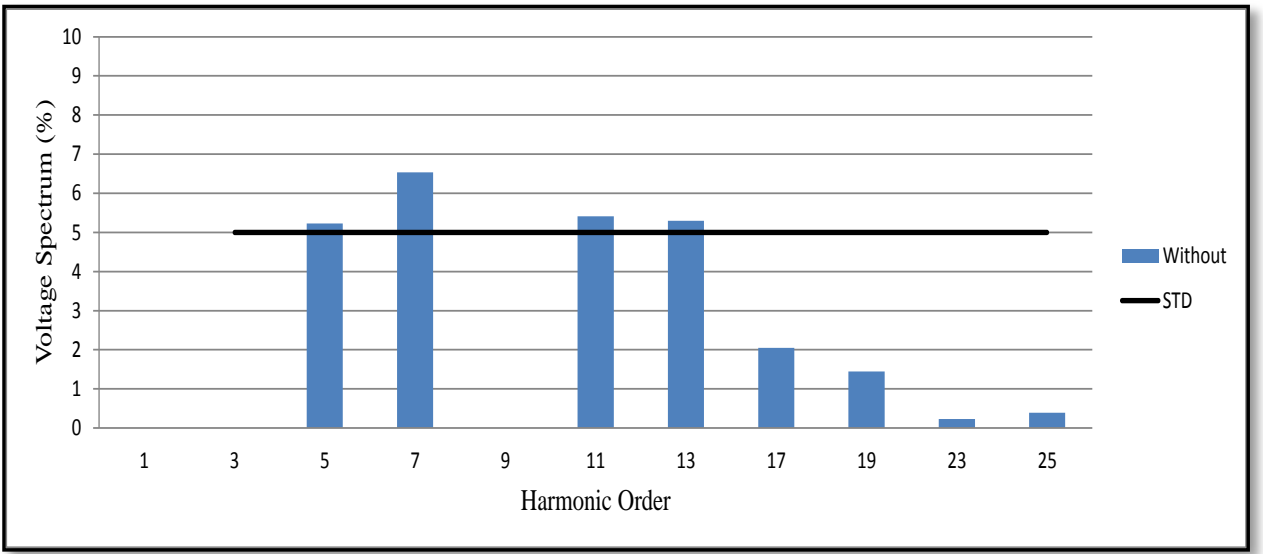

Figure 4. Harmonic spectrum of the PCC without filters

In the harmonic spectrum, there are significant levels of harmonic ranks 5th, 7th, 11th, 13th. Figure 5 presents the voltage waveforms distortion of the PCC without any technical solution addition.

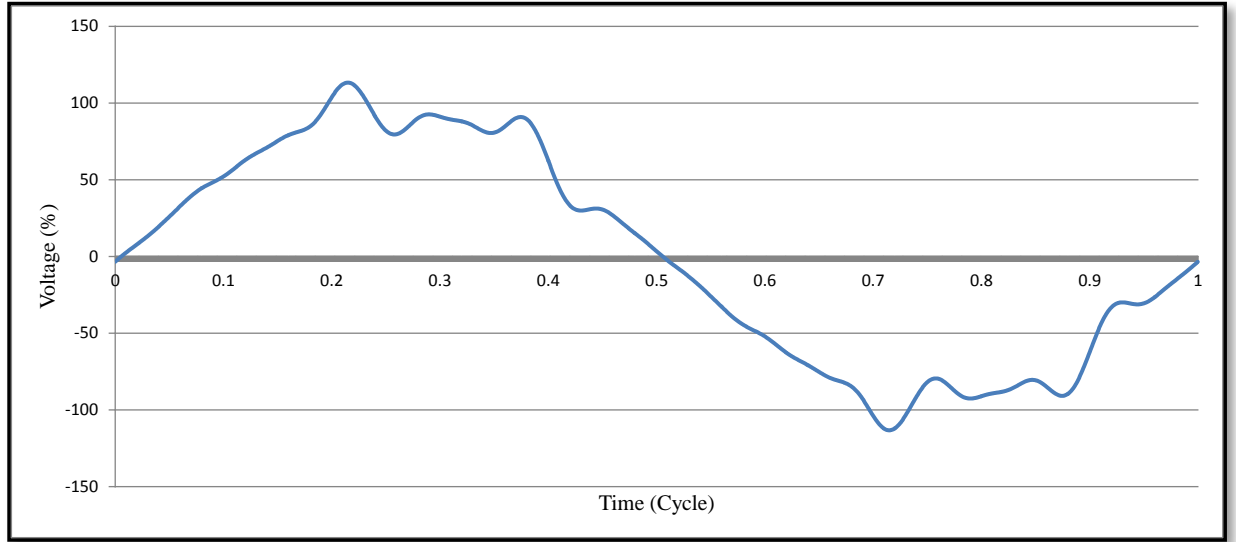

Figure 5. Voltage waveforms of the PCC without filters

The second step in the simulation is to solve the issue caused by the grid. The solution is to connect a passive harmonic filter in the PCC bus to reduce this order. The harmonic analysis simulation is presented in Figure 6 and the results for THD. The next table shows the data of harmonic filter:

Table 2. Data of Harmonic Filter

\begin{tabular}{cccc}
\hline & 5 th & 7 th & 11 th \\
\hline $\mathrm{L}(\mathrm{uH})$ & 157.24 & 82.44 & 33.42 \\
$\mathrm{C}(\mathrm{uF})$ & 2741 & 2741 & 2741 \\
\hline
\end{tabular}




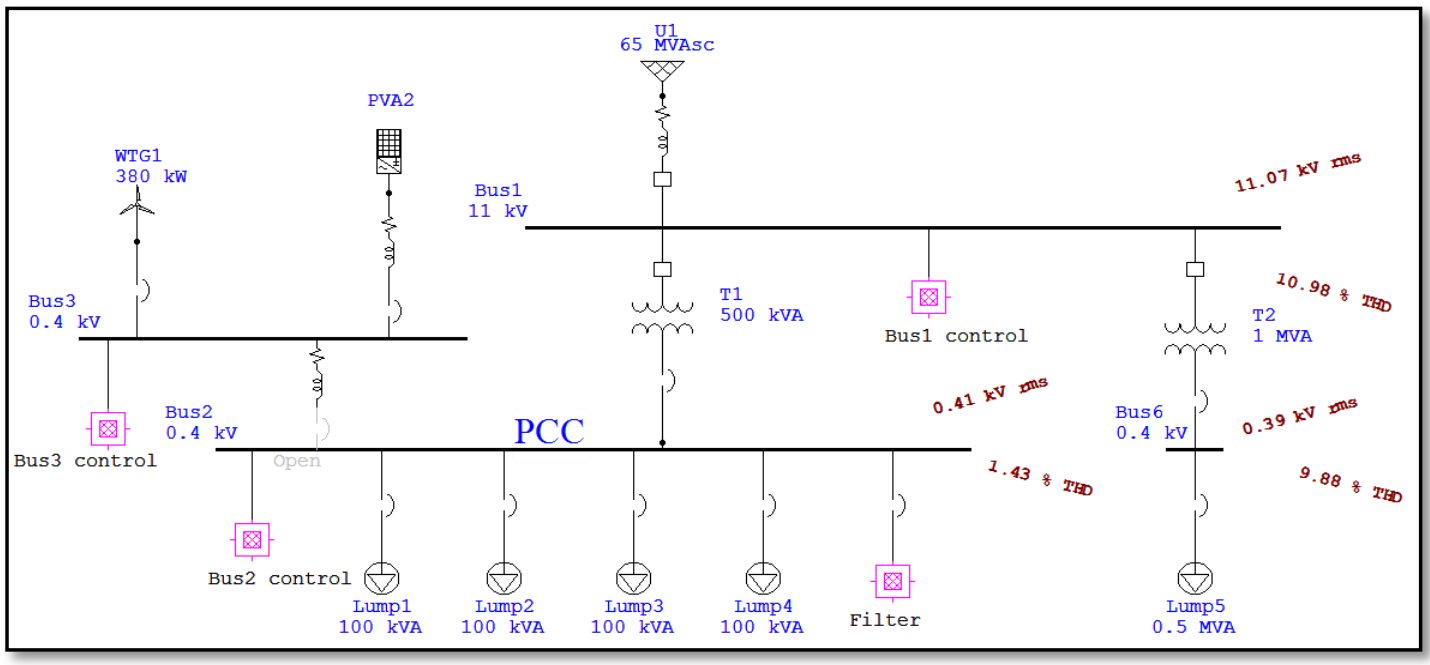

Figure 6. Harmonic flow simulation with filters

Figure 6 shows the THD values, which have a large decrease in bus 2 after connected the filters. Figure 7 represents the harmonic spectrum level of the voltage waveform of the PCC with single-tuned passive filter.

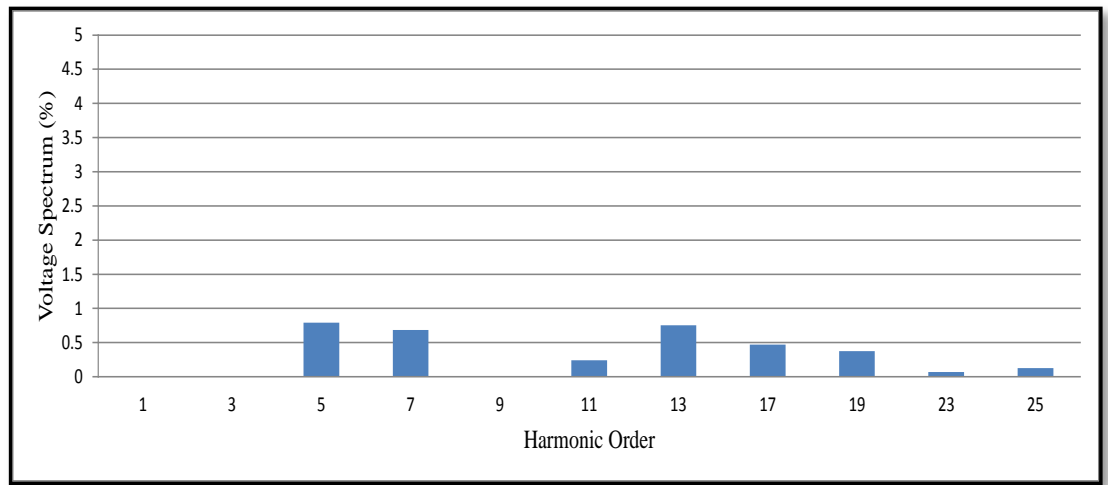

Figure 7. Harmonic spectrum of the PCC with filters

In the harmonic spectrum, there are found significant decrease for the values of harmonic ranks. Figure 8 presents the voltage waveforms distortion of the PCC with filters.

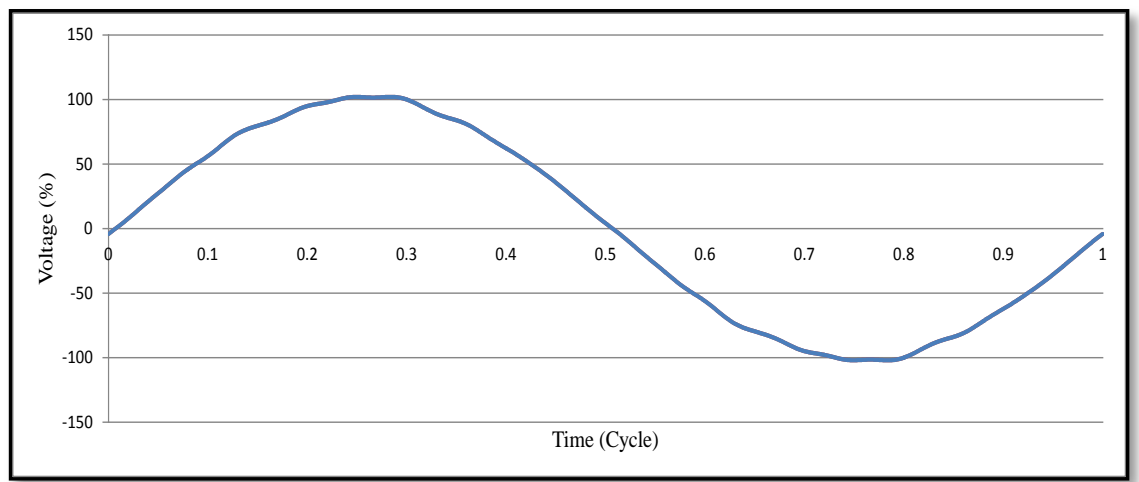

Figure 8. Voltage waveforms of the PCC with filters 
In Figure 8, there are improved voltage waveforms, a profile which resembles much to the sinusoidal. This smoothness is created by connecting harmonic filters after identifying the issues caused by grid.

Case 2: Harmonic from Renewable energy:

The source of harmonic in renewable energy is the wind and Photovoltaic (PV) and effect on the PCC, and the grid is disconnected. The harmonic power flow simulation is shows in Figure 9.

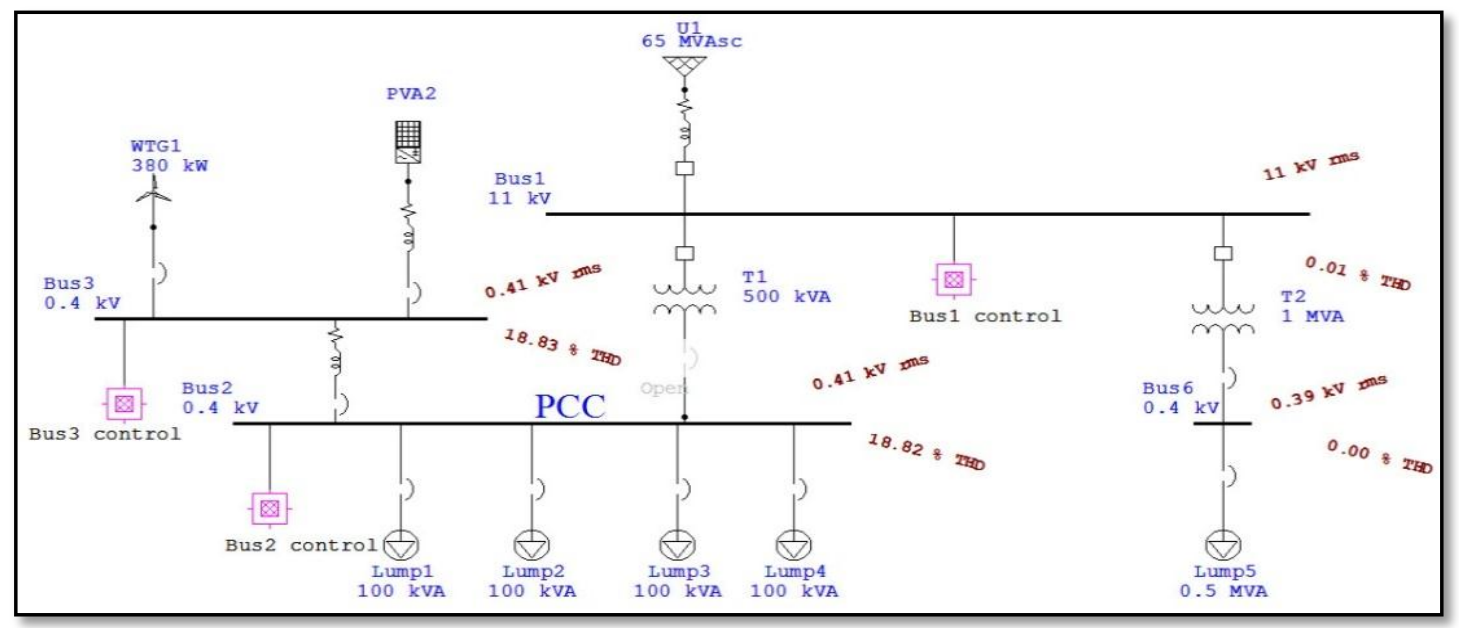

Figure 9. Harmonic power flow simulation without filters

It can be seen that there are a serious harmonic pollution in bus 2 (PCC) complies with IEEE 519 standards. Figure 10 represents the level of harmonic spectrum for the voltage of the PCC of the distribution system.

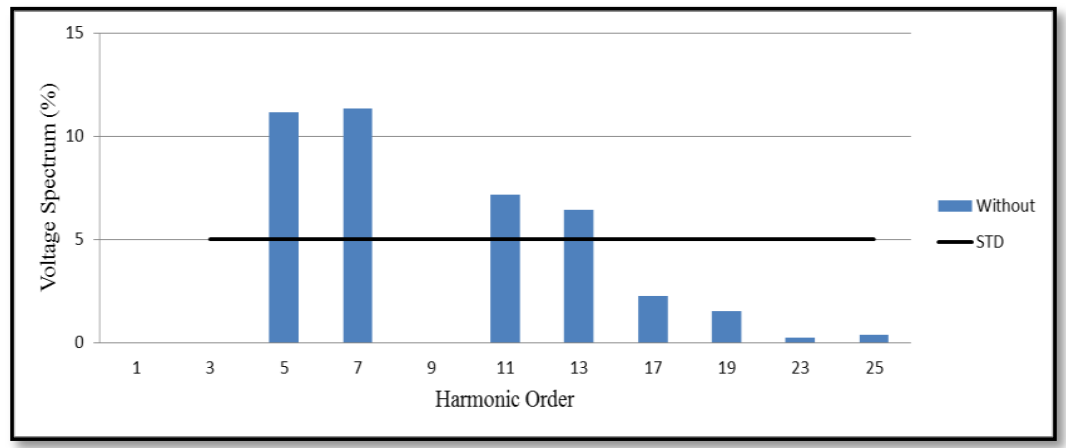

Figure 10. Harmonic spectrum of the PCC without filters

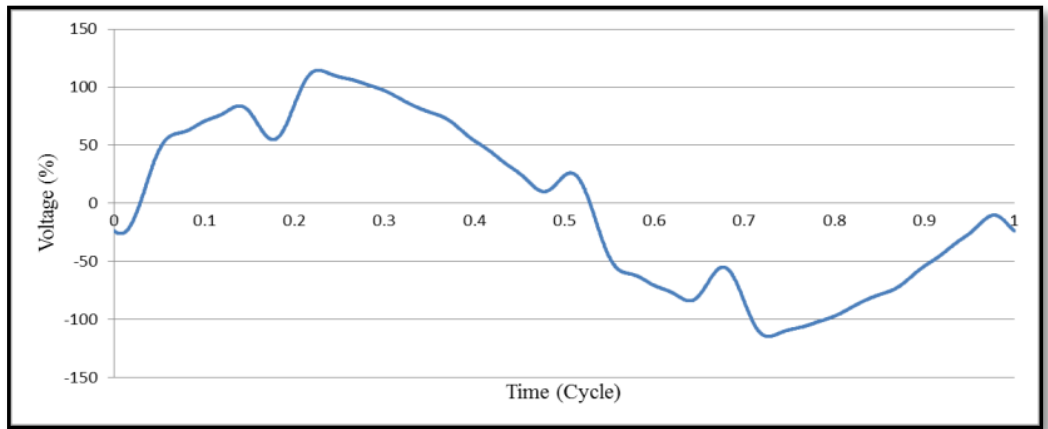

Figure 11. Voltage waveforms of the PCC without filters 
In the harmonic spectrum we have significant values of harmonic ranks 5th, 7th, 11th, 13th. Figure 11 presents the voltage waveforms distortion of the PCC without any technical solution addition.

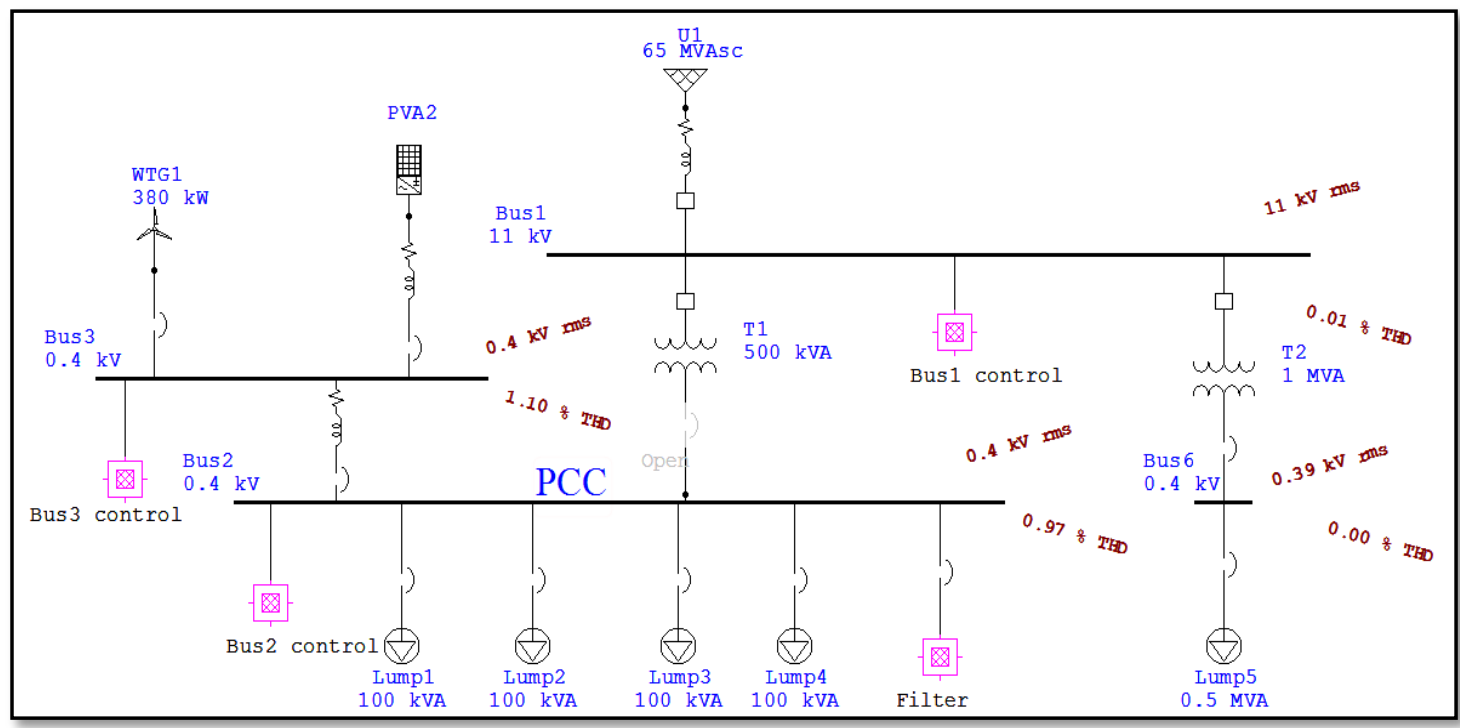

Figure 12. Harmonic flow simulation with filters

The solution is to connect a passive harmonic filter in the PCC bus to reduce this order. The harmonic flow simulation is presented in Figure 12.

Figure 12 shows the THD values, which have a large decrease in bus 2 after connected the filters. Figure 13 represents the harmonic spectrum level of the voltage waveform of the PCC with passive filters.

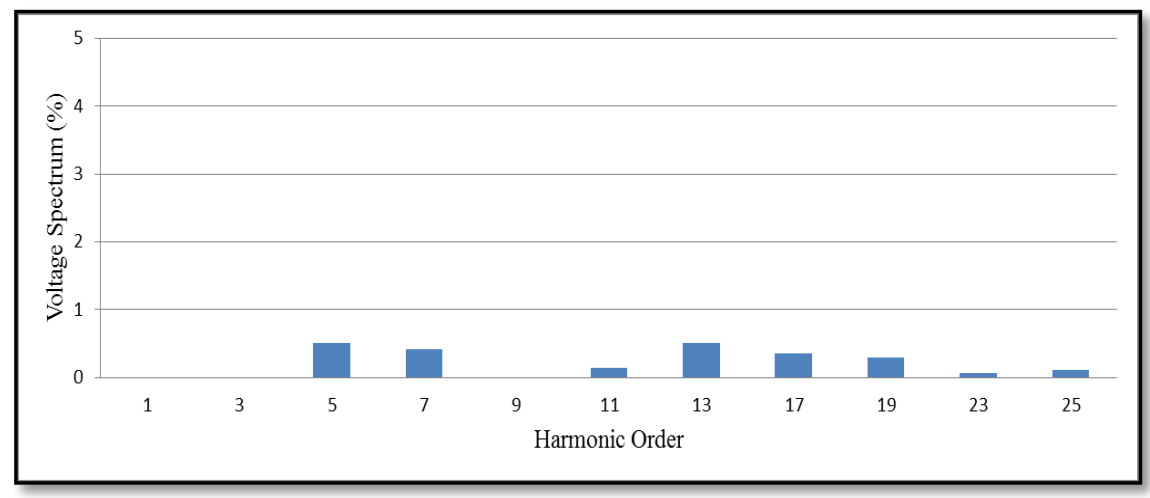

Figure13. Harmonic spectrum of the PCC with filters

In the harmonic spectrum, there are found significant decrease for the values of harmonic ranks. Figure 14 presents the voltage waveforms distortion of the PCC with filters.

In Figure 14, there are improved voltage waveforms, a profile which resembles much to the sinusoidal. This smoothness is created by connecting harmonic filters after identifying the issues caused by renewable energy. 


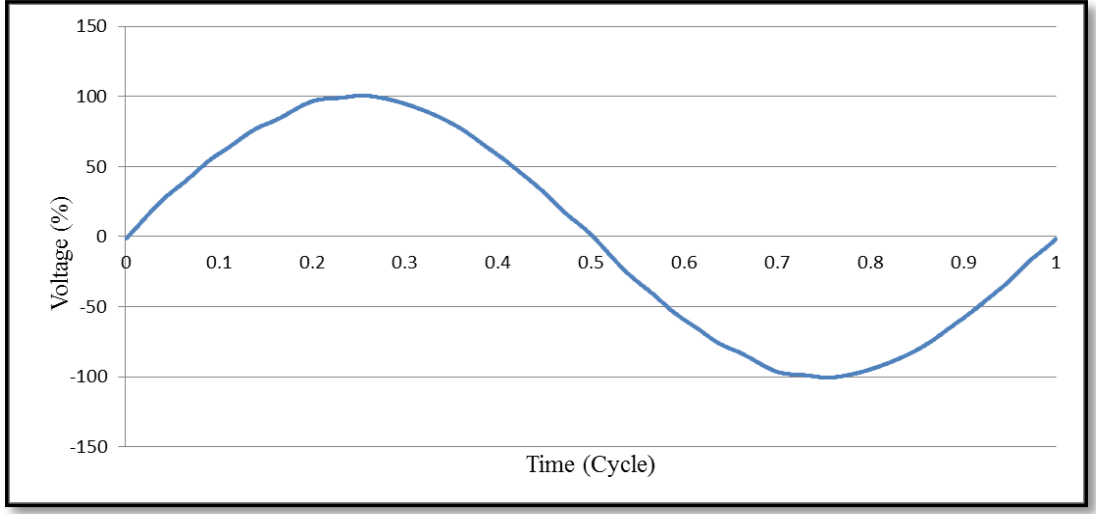

Figure 14. Voltage waveforms of the PCC with filters

\section{CONCLUSION}

Power quality and especially harmonic issues in the microgrid is presented. A single-tuned Passive Harmonic Filter is used to mitigation of harmonics in the nuclear research reactor from grid and from renewable energy source was proposed. The measurements show increasing in the 5th, 7th, 11th, 13th. Harmonics level above their permissible limits which resulted in a failure of some devices. The test system is simulated in ETAP software environment with the measured harmonic content. The proposed passive filter does not create resonance with system and offers low impedance track to harmonic current. Moreover, it yields good results in terms of total voltage and current harmonic distortion when compared with IEEE 5191992 standard.

\section{REFERENCES}

[1] M. T. Selvi, D. Gunapriya, "A Power Quality Improvement for Microgrid Inverter Operated In Grid Connected and Grid Disconnected Modes," Bulletin of Electrical Engineering and Informatics, vol. 3, no. 2, pp. 113-118, Jun. 2014.

[2] S. M. Kuchibhatla, D. Padmavathi, R. Srinivasa Rao, "Effect of Carrier Frequency in Grid Inter Connected Wind System with SSFC Controller," International Journal of Power Electronics and Drive System, vol. 9, no. 3, pp. 1349-1355, Sep. 2018.

[3] R. Saravanan, P. S. Manoharan, "Power Quality Improvement Using Unified Power Quality Conditioner Based On Particle Swarm Optimization," Bulletin of Electrical Engineering and Informatics, vol. 2, no. 1, pp. 29-34, Mar. 2013.

[4] F. H. M. Noh, M. Ab. Rahman, M. F. Yaakub, "Performance of Modified S-Transform for Power Quality Disturbance Detection and Classification," TELKOMNIKA (Telecommunication, Computing, Electronics and Control), vol. 15, no. 4, pp. 1520-1529, Dec. 2017.

[5] K. H. Youssef, "Power Quality Constrained Optimal Management of Unbalanced Smart Microgrids during Scheduled Multiple Transitions between Grid-Connected and Islanded Modes," IEEE Transactions on Smart Grid, vol. 8, no. 1, pp. 457-464, Jan. 2017.

[6] IEEE Std 1100-1999, "Recommended Practice for Powering and Grounding Electronic Equipment," Revision of IEEE Std 1100- 1992, Mar. 1999.

[7] M. H. J. Bollen, et al., "Power Quality Concerns in Implementing Smart Distribution-Grid Applications," IEEE Transactions on Smart Grid, vol. 8, no. 1, pp. 391 - 399, Jan. 2017.

[8] O. Ceaki, G. Seritan, R. Vatu, M. Mancasi, "Analysis of Power Quality Improvement in Smart Grids," 10th International Symposium on Advanced Topics in Electrical Engineering (ATEE), pp. 797-801, Mar. 2017.

[9] M. R. Yusoff, et al., "An Analysis of Harmonic and Interharmonic Contribution of Electric Arc Furnace by Using Periodogram," International Journal of Electrical and Computer Engineering (IJECE), vol. 7, no. 6, pp. 3753-3760, Oct. 2017.

[10] N. Safitri, "Harmonic Impact in Induction Generator Voltage Using Thyristor Control Reactor," Telkomnika, vol. 16, no. 3, pp. 1054-1060, Jun. 2018.

[11] M. Jauhari, D. C. Riawan, M. Ashari, "Control Design For Shunt Active Power Filter Based On P-Q Theory in Photovoltaic Grid-Connected System," International Journal of Power Electronics and Drive System (IJPEDS), vol. 9, no. 3, pp. 1064-1071, Sep. 2018.

[12] T. Firmansyah, A. Maulana, V. Dewanto, "Shunt Active Power Filter Based on PQ Theory with Multilevel Inverters for Harmonic Current Compensation," TELKOMNIKA (Telecommunication, Computing, Electronics and Control), vol. 15, no. 4, pp. 1632-1640, Dec. 2017. 
[13] A. Chidurala, T. K. Saha, N. Mithulananthan, Bansal RC, "Harmonic Emissions in Grid Connected PV systems: A Case Study on A Large Scale Rooftop PV Site," 2014 IEEE PES General Meeting|Conference \& Exposition, pp. 1-5, Jul. 2014.

[14] D. G. Stănescu, M. E. Ardeleanu, A. C. Stan, "Designing, Simulation And Testing Of Low Current Passive Filters Used In The Didactic Activity," International Conference on Modern Power Systems (MPS), pp. 1-4, Jun. 2017.

[15] M. Huang, X. Wang, P. C. Loh, F. Blaabjerg, "Design of LLCL-filter for Grid-Connected Converter to Improve Stability and Robustness," IEEE Applied Power Electronics Conference and Exposition (APEC), vol. 31, no. 5, pp. 3958-3967, May. 2017.

[16] S. N. A. L. Yousif, M. Z. C. Wanik, A. Mohamed, "Implementation of Different Passive Filter Designs For Harmonic Mitigation," PECon 2004. Proceedings. National Power and Energy Conference, pp. 229-234, Nov. 2004.

[17] M. A. Chitsazan, A. M. Trzynadlowski, "Harmonic Mitigation in Interphase Power Controller Using Passive FilterBased Phase Shifting Transformer," IEEE Energy Conversion Congress and Exposition (ECCE), pp. 1-5, Sep. 2016.

[18] Z. A. Memon, M. A. Uquaili, M. A. Unar, "Harmonics Mitigation of Industrial Power System Using Passive Filters," Mehran University Research Journal of Engineering \& Technology, vol. 31, no. 2, pp. 355-360, Apr. 2012.

[19] H. Hu, Z. He, S. Gao, "Passive Filter Design for China High-Speed Railway with Considering Harmonic Resonance and Characteristic Harmonics," IEEE Transactions on Power Delivery, vol. 30, no. 1, pp. 505-514, Feb. 2015.

[20] D. M. Soomro, M. M. Almelian, "Optimal Design of a Single Tuned Passive Filter to Mitigate Harmonics in Power Frequency," ARPN Journal of Engineering and Applied Sciences, vol. 10, no. 19, pp. 9009- 9014, Oct. 2015.

[21] J. C. Das, "Passive Filters-Potentialities and Limitations," IEEE Transactions on Industry Applications, vol. 40, no. 1, pp. 232-241, Feb. 2004.

[22] Y. S. Cho, H. Cha, "A Single-Tuned Passive Harmonic Filter Design Using Transfer Function Approach for Industrial Process Application," International Journal of Mechatronics and Automation, vol. 1, no. 2, pp. 90-96, Jan. 2011.

[23] D. Bula, M. Pasko, "Hybrid Power Filter with Single Tuned Passive Filter-Dynamical Properties," International School on Nonsinusoidal Currents and Compensation, pp. 80-83, Jun. 2010.

[24] Y. Y. Hong, C. S. Chiu, S. W. Huang, "Multi-Scenario Passive Filter Planning in Factory Distribution System by Using Markov Model and Probabilistic Sugeno Fuzzy Reasoning," Applied Soft Computing, vol. 41, pp. 352-361, Apr. 2016.

[25] F. S. Dos Reis, et al., "Harmonic Mitigation in Wind Turbine Energy Conversion Systems," 37th IEEE Power Electronics Specialists Conference, pp. 1-7, Jun. 2006. 